\title{
Thirty-Two Case Reports of Synchronous Hematological Malignancy and Solid Tumor
}

\section{Eş Zamanlı Hematolojik Malignite ve Solid Tümörü Olan Otuz Iki Olgunun Analizi}

\author{
(1) Sha Liu1 ${ }^{1}$, (1) Xudong Wei ${ }^{1}$, (1) Yuanyuan Xiong2, (1) Ruihua $\mathrm{Mi}^{2}$, (1) Qingsong Yin² \\ ${ }^{1}$ The Second Affiliated Hospital of Zhengzhou University, Department of Hematology, Zhengzhou, P.R. China \\ 2The Affiliated Cancer Hospital of Zhengzhou University, Department of Hematology, Zhengzhou, P.R. China
}

\section{To the Editor,}

Synchronous multiple primary cancer (SMPC) is defined as two or more malignancies diagnosed within 6 months of each other [1]. Its incidence is low, while the simultaneous occurrence of a hematological malignancy and a solid tumor is even less common with only cases reports provided $[2,3,4,5,6]$. We analyzed 32 patients with a synchronous hematologic malignancy and solid tumor at The Affiliated Cancer Hospital of Zhengzhou University from June 2012 to June 2018.

Patients and disease characteristics are shown in Table 1. These 32 patients included 17 males and 15 females. The median age at diagnosis was 58.5 years (range: $30-81$ years). The incidence of SMPC in our center was approximately $0.05 \%$, while this rate was reported as $0.5 \%$ in the literature [5]. The difference in this incidence might be attributable to differences in geography, environment, race, or various diagnostic criteria or, more importantly, the experience of the clinicians or the examination methods between studies.

The median interval between the diagnoses of these 2 primary malignancy types was 0.2 months (range: 0-5.3 months). Of the 32 cases, 2 patients were lost to follow-up while the other 30 patients completed the treatment: 3 cases with complete remission (CR), 9 cases with stable disease (SD), recurrence of gastric cancer in 1 case, 1 case of lymphoma recurrence, and 16 cases of death. The median overall survival (OS) of the 32 patients was 17.7 months (range: 1.3-68 months). Among the 16 deceased patients, there were 8 patients with a median age of 60.5 years (range: $44-78$ years) who survived less than 10 months, and 4 of them had reported a family history of cancer. Eight patients were diagnosed with hematologic malignancies or solid tumors of stage III or IV. Among these 8 patients, 3 patients died early after surgery, 3 patients died of pulmonary infection after radiotherapy and chemotherapy, and 2 patients died of primary disease progression.

The pathogenesis of SMPC is not completely clear. Tabor et al. [7] found that tumors of different types and different tissues might originate from identical precancerous lesions. An
Argentine study group found that 32\% of multiple primary cancer patients reported a family history of cancer [8]. Genetic instability may play an important role in the development of multiple primary cancers. Based on the detection of replication errors on microsatellite loci, Horii et al. [9] found that genetic defects in the mismatch repair system represent a high-risk factor for multiple primary cancer patients. We identified 8 patients whose first-degree relatives had experienced malignant tumors in our study.

No standard treatment options are available for synchronous hematological malignancies and solid tumors. The degree of malignancy of each tumor, the response of each tumor to therapy, the therapy indications, and the general condition of the patient should be considered simultaneously. For patients who were diagnosed with a solid tumor and indolent lymphoma such as mucosa-associated lymphoid tissue lymphoma or marginal zone lymphoma, chemotherapy or 1-131 radiotherapy was performed first to treat the solid tumor. However, for patients who were diagnosed with an early-stage solid tumor and highly aggressive lymphoma such as diffuse large B-cell lymphoma or anaplastic large-cell lymphoma, after surgical removal of the solid tumor, chemotherapy and sequential hematopoietic stem cell transplantation were administered to treat the lymphoma and at the same time regular postoperative follow-up for the solid tumor was performed.

Keywords: Synchronous multiple primary cancer, Hematological malignancy, Solid tumor

Anahtar Sözcükler: Senkron çoklu primer kanser, Hematolojik malignite, Solid tümör

Conflict of Interest: All authors have read and approved the contents of the manuscript, and the submission is not under review at any other publications and is not plagiarized. None of the authors have a direct financial interest to disclose.

Financial Disclosure: This study was financially supported with funds provided by the National Natural Science Foundation of China (No. 81170520) to Xudong Wei. 


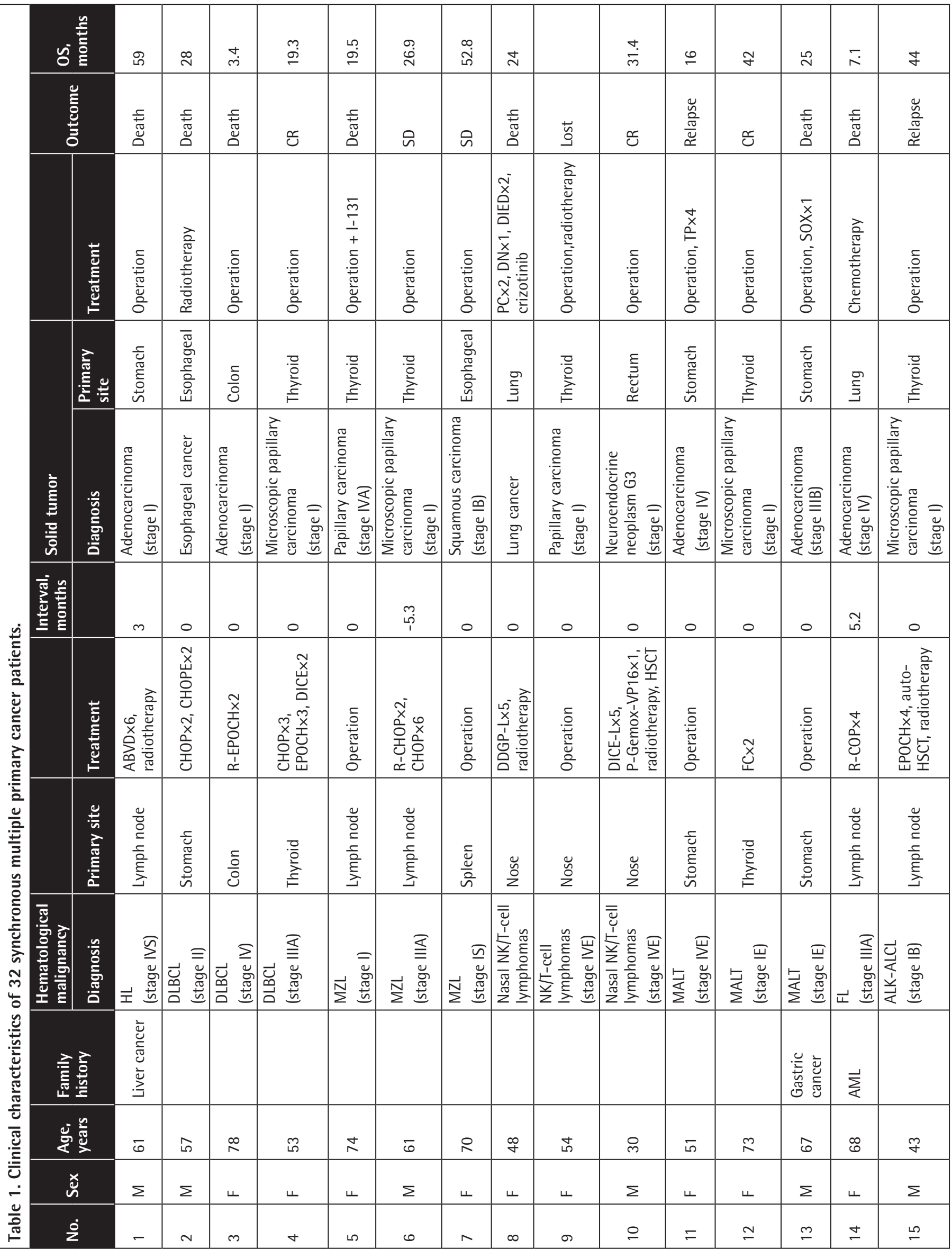




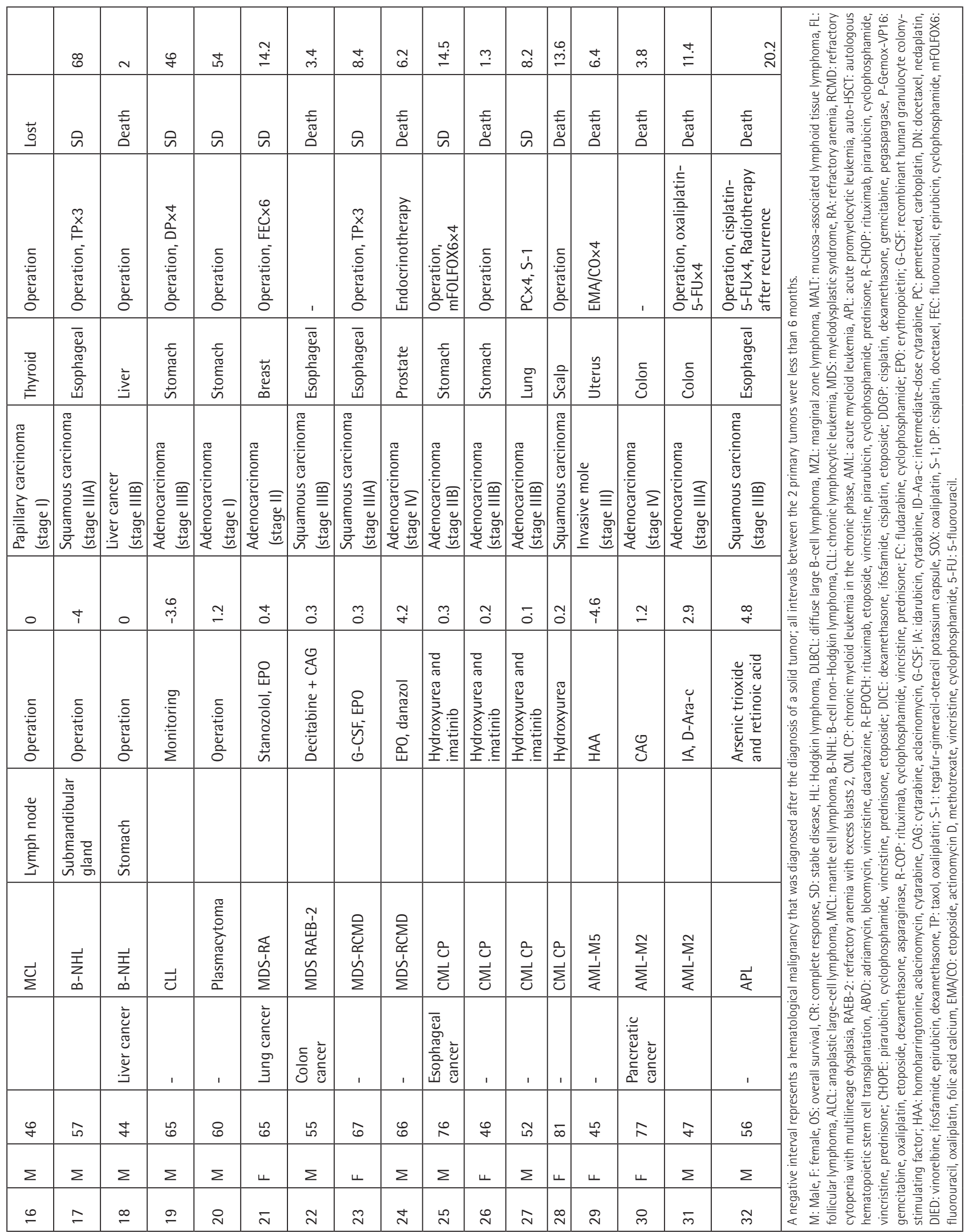




\section{References}

1. Warren $\mathrm{CS}$, Gates 0 . Multiple primary malignant tumors: a survey of the literature and a statistical study. Am J Cancer 1932;16:1358-1414.

2. Comez G, Pehlivan Y, Kalender ME, Sevinc A, Sari I, Camci C. Synchronous Hodgkin's disease and gastric adenocarcinoma. Oncology 2007;73:422-425.

3. Varadarajan R, Ford L, Sait SN, Block AW, Barcos M, Wallace PK, Ramnath N, Wang ES, Wetzler M. Metachronous and synchronous presentation of acute myeloid leukemia and lung cancer. Leuk Res 2009;33:1208-1211.

4. Yalçıntaş Arslan U, Öksüzoğlu B, Onder FO, Irkkan C, Üyetürk U, Gökbayrak $\mathrm{N}$, Alkış N. Concomitant Hodgkin's lymphoma and gastric adenocarcinoma: a rare coincidence. Med Oncol 2011;28:251-254.

5. Cui Y, Liu T, Zhou Y, Ji Y, Hou Y, Jin W, Feng Y. Five cases report of solid tumor synchronously with hematologic malignancy. Cancer Res Treat 2012;44:63-68.
6. Huang Z, Wu M, Yang H, Yu H, Gong L, Miao L, Lei T, Fan Y. Malignant lymphoma simultaneously combined with other solid tumors: four cases report and literature review. Zhonghua Xue Ye Xue Za Zhi 2014;35:345-347.

7. Tabor MP, Brakenhoff RH, Ruijter-Schippers HJ, Van Der Wal JE, Snow $\mathrm{GB}$, Leemans $\mathrm{CR}$, Braakhuis BJ. Multiple head and neck tumors frequently originate from a single preneoplastic lesion. Am J Pathol 2002;161:10511060.

8. Ares SL, Polo S, Ezcurdia L, Tognelli F, Mussini S, Gercovich E, Rivarola N, Morgenfeld E, Gil Deza E, Gercovich FG. Multiple primary cancer in adults (MPCA). ASCO Meeting Abstracts 2006;24(Suppl):16027.

9. Horii A, Han HJ, Shimada M, Yanagisawa A, Kato Y, Ohta H, Yasui W, Tahara E, Nakamura Y. Frequent replication errors at microsatellite loci in tumors of patients with multiple primary cancers. Cancer Res 1994;54:3373-3375.

\title{
Successful Outcome of a Case of Acute Myeloid Leukemia with $\mathbf{t}(8 ; 21) / A M L-E T O$ Following Langerhans Cell Histiocytosis
}

\author{
Langerhans Hücreli Histiositozunu Takiben Gelişen t(8;21) Akut Myeloid Lösemi Olgusunun \\ Başarılı Tedavisi
}

\author{
(1) Guangqiang Meng, (1) Jingshi Wang, (1) Jiancheng Huang, (1) Yini Wang, (1) Na Wei, (1) Zhao Wang
}

Beijing Friendship Hospital, Capital Medical University, Beijing, China

To the Editor,

The occurrence of Langerhans cell histiocytosis (LCH) and acute myeloid leukemia (AML) in the same case has been reported occasionally. We report a new case of AML with $t(8 ; 21) / A M L-$ ETO in an adolescent after LCH. To our knowledge, this is the first description of AML with $\mathrm{t}(8 ; 21) / \mathrm{AML}-\mathrm{ETO}$ after LCH diagnosis and therapy.

A 15-year-old boy was diagnosed with LCH in October 2010. He presented with a 1-year history of a skull mass. After 9 cycles of ifosfamide, vincristine, etoposide, and prednisone, the skull mass disappeared. Two years later, the patient presented to the Hematology Department of Beijing Friendship Hospital with progression of his disease in the form of lumber fracture. The mutation BRAF V600E was negative. After relapse of $\mathrm{LCH}$, he received 6 cycles of etoposide and prednisone and 1 cycle of etoposide, prednisone, cyclophosphamide, and vincristine. On 12 March 2013, he received an autologous hematopoietic stem cell transplant. When he came to the clinic with complaints of dizziness on 20 November 2017, a routine blood examination was performed with the following results: white blood cell count, $6.3 \times 10^{9} / \mathrm{L}_{\text {; }}$ hemoglobin, $60 \mathrm{~g} / \mathrm{L}_{i}$ and platelet count, $12 \times 10^{9} /$ L. Bone marrow biopsy showed $69 \%$ myeloblasts, and Auer rods were found. The immunophenotype profile of the blast cells was CD34 (++), CD13 (+), CD33 (++), CD117 (++), CD38 (+), CD15 (+), HLA-DR (++), MPO(+). Cytogenetic analysis revealed 46, XY, t(8;21)(q22;q22)[20]. The AML-ETO and WT1 genes were positive. The patient responded well to induction chemotherapy. Standard DA chemotherapy (daunorubicin and cytarabine) was given and the boy achieved complete response (CR) after one cycle. After an additional cycle of DA consolidation chemotherapy, he received an HLA-identical sibling allogeneic hematopoietic stem cell transplant (HSCT). He received a conditioning protocol composed of busulphan and cyclophosphamide, and he was given fluconazole and acyclovir as infection prophylaxis and cyclosporine and mycophenolate mofetil as graft-versus-host disease prophylaxis. Up to 30 March 2019, the patient was in a state of persistent CR for 16 months after the diagnosis of the AML, and the AML-ETO and WT1 genes were negative. 